\title{
GOLD CONDUCTOR PASTES FOR HIGH DENSITY CIRCUIT
}

\author{
SHIRO KADOTA and KOSHIRO SHIBATA \\ Electronics Metal Division, Sumitomo Metal Mining Co., Ltd., 1-6-1, Suehiro-cho, Ohme-shi, Tokyo, \\ Japan
}

\begin{abstract}
High grade quality in fine-line printability, non-porosity of fired film and adhesion to substrate is required for gold conductor pastes applicable to multilayer or high density circuit. Many kinds of gold pastes were made by the changing of types and contents of main components such as gold powder, glass frit and organic vehicle. The important properties of the fired samples of the above pastes on alumina substrate and fired dielectric pastes were compared.

Gold paste of the mixed bond type was recognized as superior in adhesion to alumina substrate, while that of the fritless type was found superior in adhesion to the fired dielectric paste and wire bondability. It is possible to print line of $70 \mu \mathrm{m}$ width and spacing by using these gold pastes. If suitable printing conditions including screen are chosen, even $50 \mu \mathrm{m}$ line width and spacing can be made. Non-porosity measured by means of the back light porosity test and low resistivity of the samples met the requirement for the high density circuit.

In this paper, various properties of the above mentioned gold pastes which are most suitable to two different type substrates will be described. Also the relation between the properties and compositions of the samples will be discussed.
\end{abstract}

\section{INTRODUCTION}

During recent years, technology for fabricating hybrid integrated circuits has advanced, in respect to their circuit density, function multiplicity, and performance.

Up to quite recently, gold conductor paste had been used almost exclusively, and requirements on their characteristics are becoming increasingly rigorous.

With the rising prices of precious metals, gold conductor paste is being replaced by that of $\mathrm{Ag} / \mathrm{Pd}$ or further by that of base metals to a limited extent, but for high performance quality applications, gold paste is still mainly expected to be used.

The main characteristics required of gold conductor paste for high density circuits are as follows.

1) Fine-line printability

2) Non-porosity of fired films

3) High conductivity

4) Adhesion to substrates or to dielectrics

5) Wire bondability

In view of the increasing demand for multi-layer systems, various types of gold paste compositions were tested with respect to these characteristics in conjunction with alumina substrates and dielectrics. Although many papers on fine-line printability of gold conductor paste have been published ${ }^{2,3}$ already, most of these papers regard $100-125 \mu \mathrm{m}$ as the limit for line width and spacing. In the present experimental study, finer line printability was pursued.

\section{SAMPLES}

Depending on the composition, gold paste is classified into following types.

1) Fritted type; Gold powder, Glass frit and Vehicle

2) Fritless type; Gold powder, Oxide additive and Vehicle

3) Mixed bond type; Gold powder, Glass frit, Oxide additives and Vehicle.

Some 150 types of sample paste with various combinations of the main compositions, as described below, were prepared and tested.

Gold powder: Several powder samples were evaluated for gold paste use. As a result of preliminary test, gold powder consisting mainly of platelets was found inferior to that of spheres from the points of printability and flake generation during blending process. Only spherical type gold powder was used for this test. Photo 1 shows surface of two typical gold powder samples used this time. 


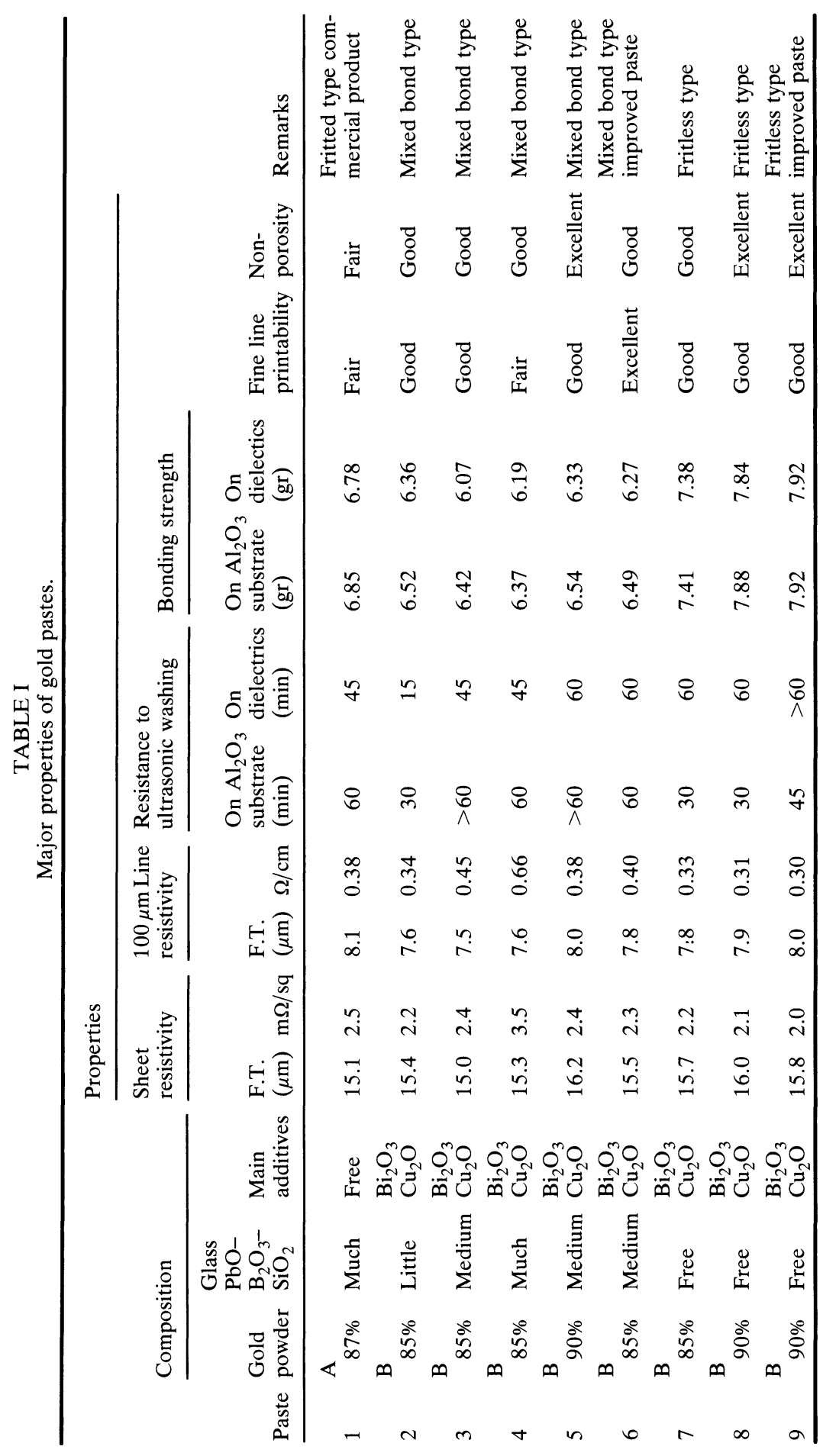




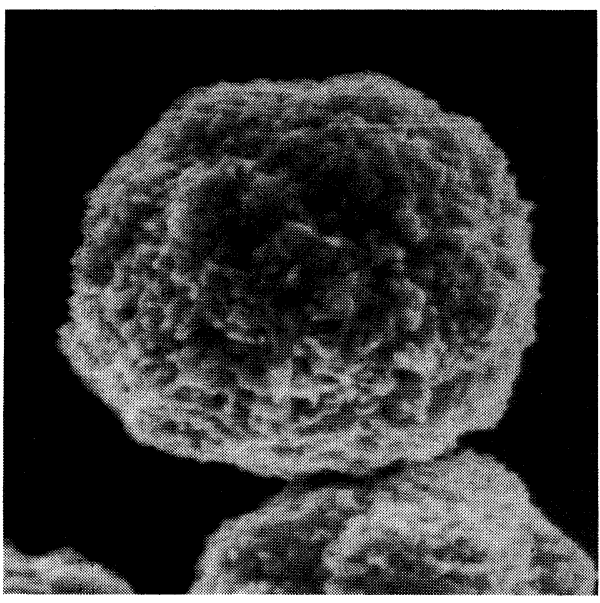

1) Powder A

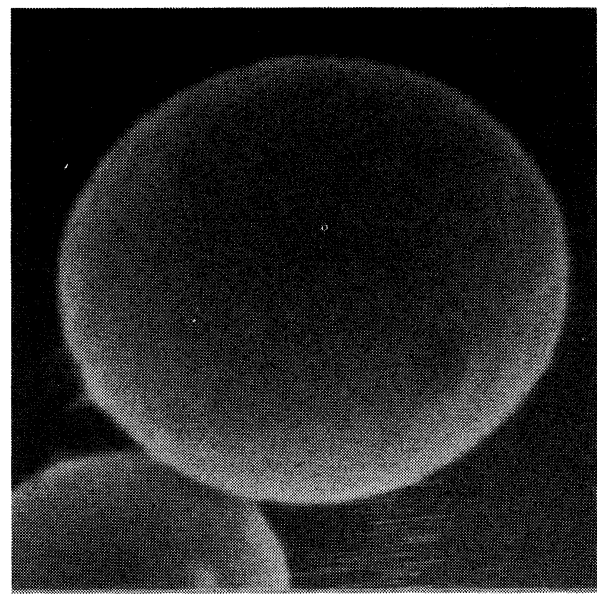

2) Powder B

PHOTO 1 Electron micrographs of gold powders $(20,000 \times)$.

Glass frit: Several samples were made of $\mathrm{PbO}-\mathrm{B}_{2} \mathrm{O}_{3}-\mathrm{SiO}_{2}$ type glasses, each with different chemical composition and grain size.

Vehicle: Several samples were made, each with various composition.

Additive: Various oxides including $\mathrm{Bi}_{2} \mathrm{O}_{3}, \mathrm{Cu}_{2} \mathrm{Q}$, $\mathrm{SiO}_{2}, \mathrm{MgO}$, and $\mathrm{CdO}$, which were known for their specific effects, were tested.

The compositions of the main nine types of sample gold paste are shown in Table I.

As mentioned before, these gold paste samples were tested not only on alumina substrates, but also on dielectric layers, in consideration of multi-layer applications.

The main characteristics of the dielectric paste used are shown in Table II.

This dielectric paste containing glass frit component to which filler was added as a part had good structural stability and thermal conductivity.

TABLE II

Dielectric paste

\begin{tabular}{ll}
\hline Composition & $\mathrm{PbO}-\mathrm{B}_{2} \mathrm{O}_{3}-\mathrm{SiO}_{2}$ Glass + metal oxide \\
\hline Dielectric constant & $9 \sim 10(1 \mathrm{MHz})$ \\
Insulation resistance & $\geqq 10^{10} \Omega(100 \mathrm{~V} \mathrm{DC})$ \\
$Q$ Factor & $\geqq 500(1 \mathrm{MHz})$ \\
Breakdown voltage & $>500 \mathrm{~V} \mathrm{AC} / 40^{\mu \mathrm{m}}$ \\
Thermal conductivity & $0.025 \mathrm{~W} / \mathrm{cm}^{\circ} \mathrm{C}$ \\
Printing & Double printing \\
Firing & $935^{\circ} \mathrm{C}\left(\right.$ F.T.40 $\left.40^{\mu \mathrm{m}}\right)$ \\
\hline
\end{tabular}

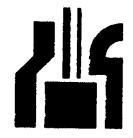

$70 \mu \mathrm{m}$ Fine line pattern (Fine line printability)

(a)

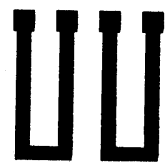

$2 \mathrm{~mm} \times 40 \mathrm{~mm}$ Line pattern (Sheet resistivity)

(c)

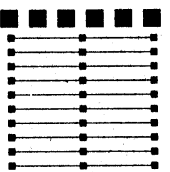

$100 \mu \mathrm{m}$ Line pattern (Line resistivity wire bonding )

(b)

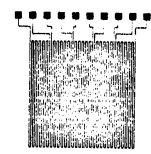

$100 \mu \mathrm{m}$ Fine line pattern (Adhesion)

(d)

FIGURE 1 Test pattern.

\section{EXPERIMENT AND RESULTS}

Nearly 150 types of sample paste were experimented with and evaluated in respect to the main characteristics that were required for applications in high density circuits.

Test samples were made of all the types of sample paste by printing and firing the test patterns shown in Figure 1 directly on alumina substrates, or on the dielectric fired films formed on alumina substrates in advance.

The preparation conditions of the test samples are shown in Table III.

The test results are as follows. 


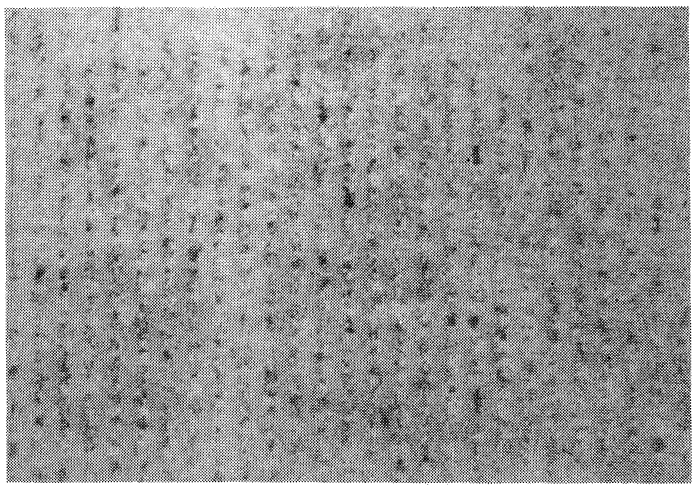

1) Paste-1

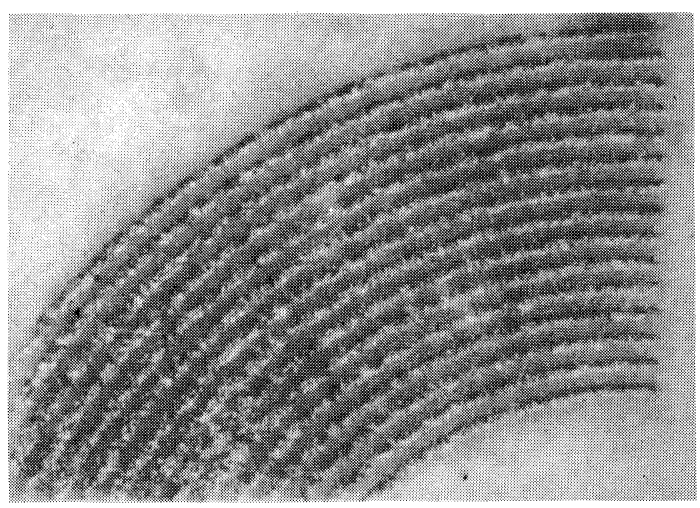

3) Paste-6

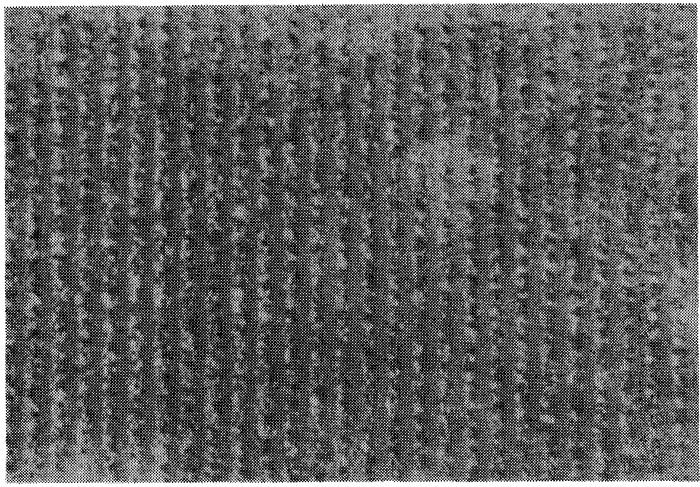

2) Paste-6

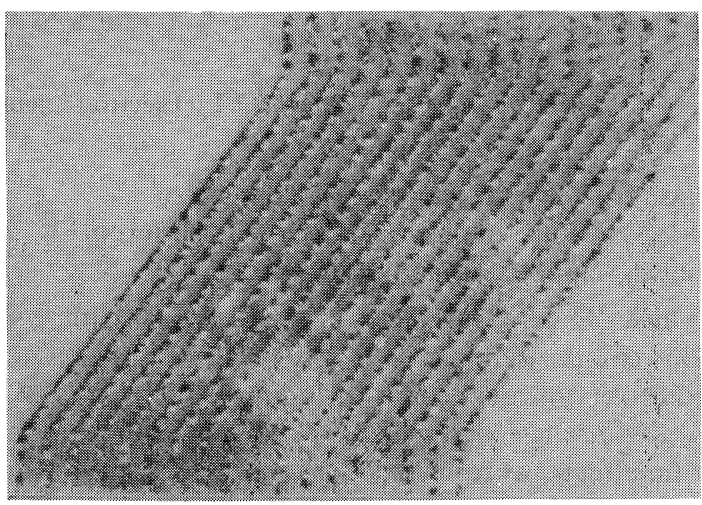

4) Paste-6

PHOTO 2 Printed and fired pattern of $70 \mu \mathrm{m}$ line width and spacing $(10 \times)$.

\subsection{Fine-line Printability}

a) Evaluation by test pattern

Photo 2 shows the specimens prepared by printing and firing Paste 1 and Paste 6 in the $70 \mu \mathrm{m}$ fine line pattern of Figure 1(a) under the conditions shown in Table III.

As can be seen, Paste 6 gave more clearly defined line edges all over, including straight line portions, $45^{\circ}$ diagonal lines, and curved lines.

Under the printing conditions given in Table III, the fine-line resolution limit for gold paste is considered to be between 70 and $100 \mu \mathrm{m}$.

When good paste, high-performance printer, and high skill of printing are combined, $50 \mu \mathrm{m}$ line width and spacing is possible.

Table IV shows the comparison of printing conditions between 70-100 $\mu \mathrm{m}$ and $50 \mu \mathrm{m}$ line width and spacing, based on an existing paper ${ }^{4,5}$ and the experimental result.
TABLE III

Test sample manufacturing condition.

1. Printing

Printer

1) Screen

Stainless steel 325 mesh, $5^{\prime \prime} \times 5^{\prime \prime}$

Angle $45^{\circ}$

Emulsion thickness $20 \mu \mathrm{m}$

2) Sqeegee

Polyurethane, 60 durometer

3) Squeegee speed

2 inches/sec

2. Substrate $\quad 96 \% \mathrm{Al}_{2} \mathrm{O}_{3}, \mathrm{sq} /$ inch

Surface roughness $2 \sim 3 \mu \mathrm{m}$

3. Viscosity $\quad 300 \sim 350 \mathrm{kcps} / 10 \mathrm{rpm}$

(Brook Field HBT)

4. Drying Belt type Peak $125^{\circ} \mathrm{C} \times 10 \mathrm{~min}$

5. Firing

Belt type Peak $935^{\circ} \mathrm{C} \times 8 \mathrm{~min}$

Photo 3 shows a sample of $50 \mu \mathrm{m}$ line width and spacing printing made under the conditions shown in Table IV.

b) Edge roughness 


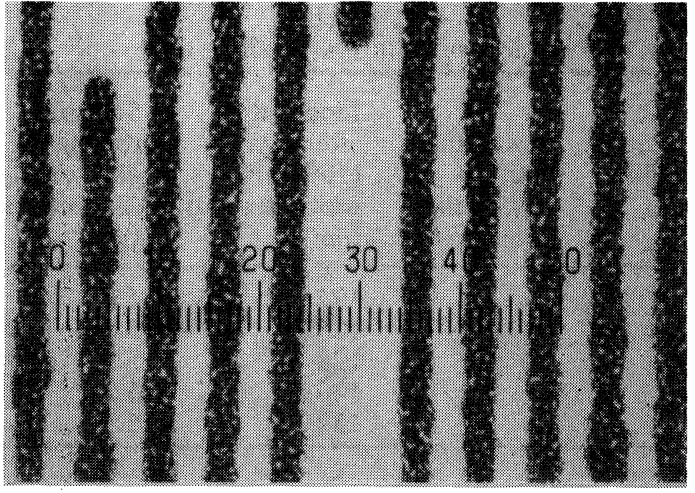

1) Back light photograph $(50 \times)$

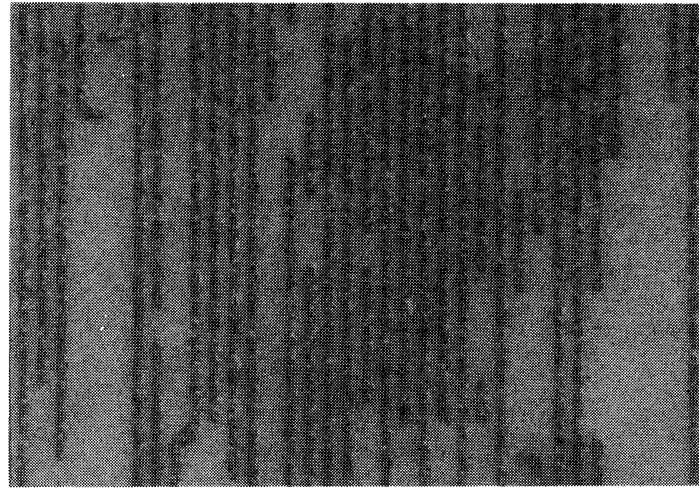

2) $(10 \times)$

PHOTO 3 Printed and fired paste of $50 \mu \mathrm{m}$ line width and spacing (Paste-6).

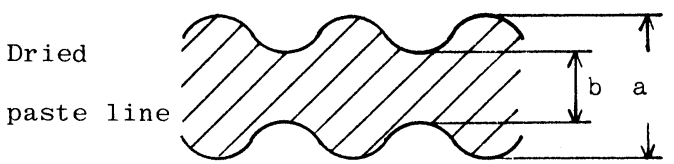

Edge roughness $=\frac{t-b}{2}$

FIGURE 2 Edge roughness.

The smoothness of printed edge lines is an important factor in fine-line printing, and is expressed in edge roughness as defined in Figure 2. While Paste 1 showed an edge roughness of $25 \mu \mathrm{m}$ max., Paste 6 showed the possibility of an edge roughness below $17 \mu \mathrm{m}$.
With respect to edge roughness, the results of the present tests were as follows.

1) Mixed bond type paste samples showed better edge roughness than fritted type paste samples.

2) The higher the gold content the more inferior the edge roughness of the printed patterns tended to become, and the optimum gold content for fritted type paste was around $85 \%$, and that for fritless type paste was around $90 \%$.

3) For the same compositions, gold powder B showed better edge roughness than gold powder $\mathrm{A}$.

4) The addition of a small amount of glass frit improved printability, but printability was adversely affected in the case of over $4 \%$ frit.

TABLE IV

Fine line printing condition.

\begin{tabular}{|c|c|c|}
\hline Printing condition & $70 \sim 100 \mu \mathrm{m}$ Fine line printing & $50 \mu \mathrm{m}$ Fine line printing \\
\hline Paste viscosity & $300 \sim 350 \mathrm{kcps} / 10 \mathrm{rpm}$ & $370 \sim 420 \mathrm{kcps} / 10 \mathrm{rpm}$ \\
\hline $\begin{array}{l}\text { Screen } \\
\text { Mesh } \\
\text { Angle } \\
\text { Emulsion }\end{array}$ & $\begin{array}{lc}\text { Stainless steel } 200 \sim 325 \text { mesh } \\
& 45^{\circ} \\
\text { Thickness } & 20 \mu \mathrm{m} \\
\text { Roughness } & 8 \mu \mathrm{m}\end{array}$ & 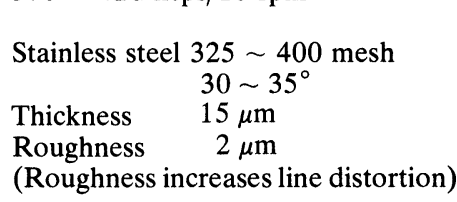 \\
\hline Squeegee material & Polyurethane, 60 durometer & Polyurethane, 70 durometer \\
\hline Squeegee speed & 2 inches/sec & $0.5 \sim 1$ inches/sec \\
\hline $\begin{array}{l}\text { Substrate } \\
\text { Surface roughness } \\
\text { Warp }\end{array}$ & $3 \sim 4 \mu \mathrm{m}$ & $\begin{array}{l}1 \mu \mathrm{m} \\
150 / \text { inch less }\end{array}$ \\
\hline $\begin{array}{l}\text { Drying } \\
\text { Levelling } \\
\text { Drying }\end{array}$ & $\begin{array}{l}5 \sim 15 \mathrm{~min} \\
125^{\circ} \mathrm{C} \times 10 \mathrm{~min}\end{array}$ & $\begin{array}{l}5 \sim 10 \mathrm{~min} \\
150^{\circ} \mathrm{C} \times 5 \sim 10 \mathrm{~min}\end{array}$ \\
\hline
\end{tabular}


5) A small amount of $\mathrm{Bi}_{2} \mathrm{O}_{3}$ and $\mathrm{CdO}$ used as additives showed good results, but $\mathrm{MgO}$ adversely affected printability.

c) Line spreading

Line spreading $\Delta \mathrm{L}$ is defined as follows.

$$
\Delta \mathrm{L}=\mathrm{L}_{1}-\mathrm{L}_{0}
$$

where $\mathrm{L}_{0}=$ width of pattern line of screen

$$
\begin{aligned}
\mathrm{L}_{1}= & \text { width of printed } \\
& \text { line (after drying). }
\end{aligned}
$$

When the line spreading $\Delta \mathrm{L}$ was evaluated with line width of $100 \mu \mathrm{m}$ in the pattern shown in Figure 1(b), following results were obtained, $\Delta \mathrm{L}=10 \sim 45 \mu \mathrm{m}$ for paste $1, \Delta \mathrm{L}=10 \sim 30 \mu \mathrm{m}$ for Paste 6 and $\Delta \mathrm{L}=10 \sim 35 \mu \mathrm{m}$ for Paste 9 .

The duration of levelling at room temperature after printing had a great influence on line spreading.

The comparison of line spreading values among the samples prepared with various levelling time, made of Paste 6 and using the pattern of Figure 1(b) is shown in Table V. These samples were dried in a box furnace at $150^{\circ} \mathrm{C}$.

Surface roughness was measured by SURFCOM-5 stylus type roughness meter made by Tokyo Seimitsu Kikai and the roughness factors were calculated as the difference between the mean value of five crest values and that of five valley values.

Although a shorter levelling time showed better results for restricting spreading, too short a levelling time was not feasible because of the increased surface roughness, and 5 to 15 minutes were found to give optimum results.

When still finer lines are required, a levelling time of below 10 minutes seems to be suitable.

\section{d) Shrinkage}

Line width shrinkage (L.W.S.) and film thickness shrinkage (F.T.S.) are defined as follows.

$$
\begin{aligned}
& \text { L.W.S. }=1-\frac{\text { Width of } 100 \mu \text { line after firing }}{\text { Width of } 100 \mu \text { line after drying }} \\
& \text { F.T.S. }=1-\frac{\text { Film thickness after firing }}{\text { Film thickness after drying }}
\end{aligned}
$$

\begin{tabular}{|c|c|c|c|}
\hline $\begin{array}{l}25^{\circ} \mathrm{C} \\
\text { Levelling } \\
\text { time } \\
(\mathrm{min})\end{array}$ & $\begin{array}{l}\text { Box furnace } \\
150^{\circ} \mathrm{C} \\
\text { Drying time } \\
\text { (min) }\end{array}$ & $\begin{array}{l}\text { Line width } \\
\text { after drying } \\
(100 \mathrm{~m} \text { line } \\
\text { width pattern }) \\
(\mu \mathrm{m})\end{array}$ & $\begin{array}{l}\text { Surface } \\
\text { roughness } \\
\text { after drying } \\
(259 / \mathrm{mm} \text { pad }) \\
(\mu \mathrm{m})\end{array}$ \\
\hline 1 & 10 & 122 & 6.0 \\
\hline 5 & 10 & 126 & 5.5 \\
\hline 10 & 10 & 128 & 5.3 \\
\hline 15 & 10 & 130 & 5.2 \\
\hline 20 & 10 & 132 & 5.1 \\
\hline
\end{tabular}

The results of the measurements were as follows.

$\begin{array}{llll} & \text { Paste-1 } & \text { Paste-6 } & \text { Paste-9 } \\ \text { L.W.S. } & \leqq 0.15 & \leqq 0.12 & \leqq 0.11 \\ \text { F.T.S. } & \leqq 0.50 & \leqq 0.48 & \leqq 0.47\end{array}$

TABLE V

Line spreading vs. levelling time

For the same gold content, paste based on Powder B had smaller L.W.S. and F.T.S. values than paste based on Powder A. Paste containing less vehicle showed smaller L.W.S. and F.T.S. values than paste containing more vehicle.

\subsection{Non-porosity Evaluation of Fired Films}

\section{a) Back light porosity}

Fired film $15 \mu \mathrm{m}$ in thickness and $2 \mathrm{~mm}$ square in size was formed on an alumina substrate, a back light photograph of the film was taken at 100 times magnification with light applied on the reverse side, and the number of holes $1 \mathrm{~mm}$ or larger in diameter was counted for $1 \mathrm{~mm}$ square of the pad.

According to many test results, the number of the holes were $7 \sim 25$ for Paste 1, $5 \sim 13$ for Paste 6 , and up to 10 for Paste 9 . Photo 4 shows the examples.

b) Electron microphotograph of cross sections Photo 5 shows the cross sections of fired films of Paste 1, Paste 6 and Paste 9 formed on alumina substrates and on dielectrics. All the sample films were broken manually.

Although no great difference is visible in the photos, the gold grains in Paste 6 and Paste 9 were slightly more sintered than those in Paste 1.

\subsection{Electrical Resistance}

a) Line resistivity

Line resistivity was measured between 2 pads $(1 \mathrm{~mm}$ square) of 20 lines $(100 \mu \mathrm{m} \times 10 \mathrm{~mm})$ in the test patterns of Figure 1(b) and was expressed with the mean values. A digital multimeter Model TR-6655 made by Takeda Riken Kogyo was used for the measurement.

Examples of the results with the $100 \mu \mathrm{m}$ pattern and 


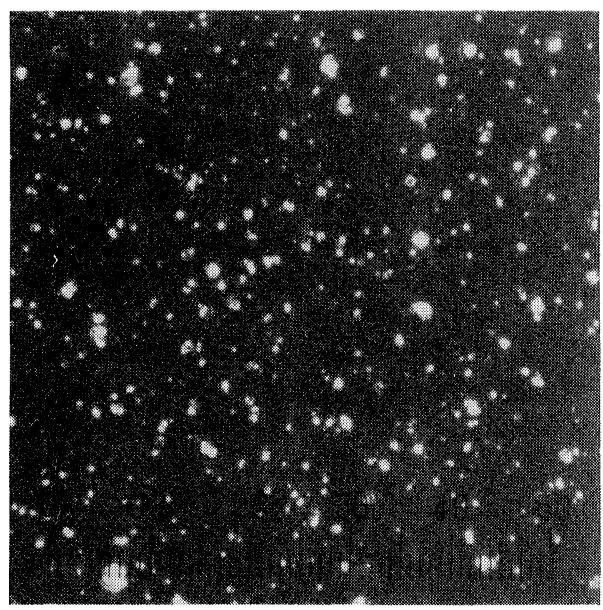

1) Paste-1

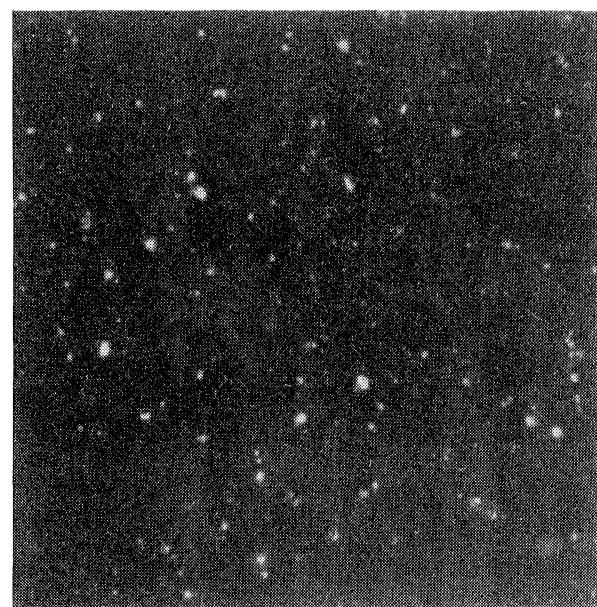

2) Paste-6

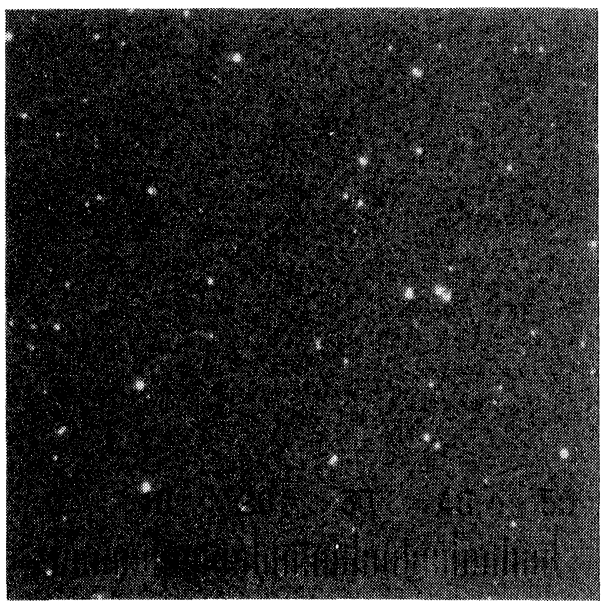

3) Paste-9

PHOTO 4 Back light photograph of 1 square $\mathrm{mm}$.

a film thickness of $7 \mu \mathrm{m}$ are shown in Table 1. As can be seen;

1) Although higher gold content resulted in lower resistance, no significant difference was observed between gold contents of 85 and $90 \%$.

For the same gold content, paste based on Powder B was lower in resistance than paste based on Powder A.

2) As might be expected, a smaller glass content was contributed to lower resistance.

3) Addition of $\mathrm{Bi}_{2} \mathrm{O}_{3}$ was effective in reducing the resistance, up to $2.0 \%$. Figure 3 shows the change in the resistance accompanying the change in $\mathrm{Bi}_{2} \mathrm{O}_{3}$ contents.

\section{b) Sheet resistivity}

With test samples made in the form of the $2 \times 40 \mathrm{~mm}$ test pattern shown in Figure 1(c), the resistance was measured with the $15 \mu \mathrm{m}$ thick film using the same instrument as used to measure line resistivity. As can be seen from the measurement results shown in Table $\mathrm{I}$, the same tendency as with line resistivity was observed.

\subsection{Adhesion to Substrate or Dielectrics}

The adhesion of fired gold film on substrates and 


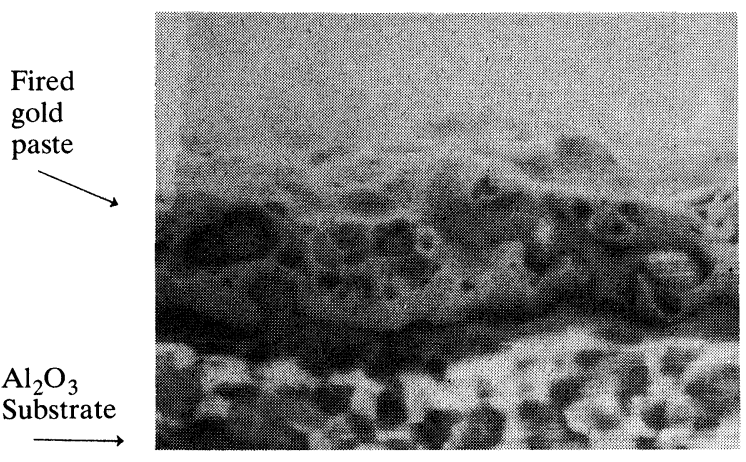

1) Paste-1 on $\mathrm{Al}_{2} \mathrm{O}_{3}$ substrate

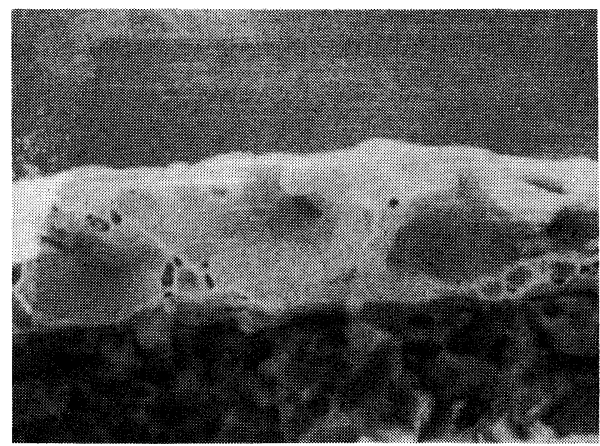

3) Paste- 6 on $\mathrm{Al}_{2} \mathrm{O}_{3}$ substrate

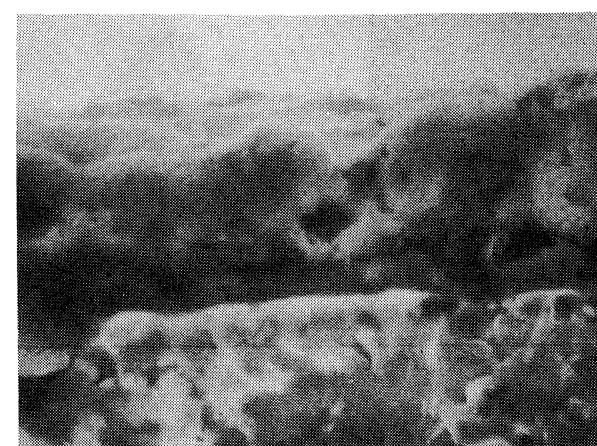

5) Paste-9 on $\mathrm{Al}_{2} \mathrm{O}_{3}$ substrate

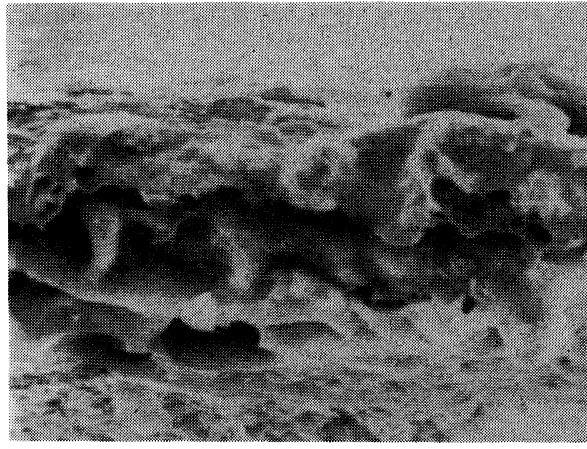

Fired

gold

paste

Fired

dielectric

paste

2) Paste-1 on fired dielectric paste

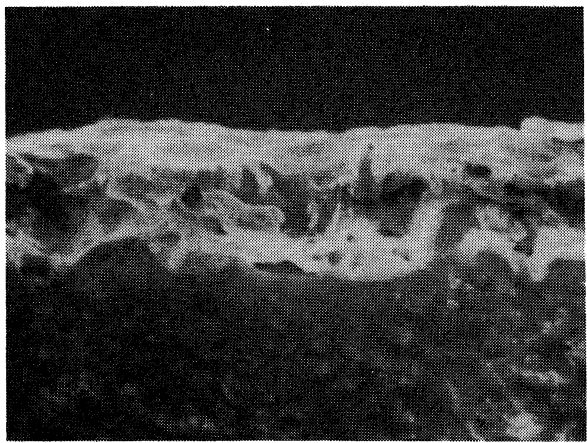

4) Paste- 6 on fired dielectric paste

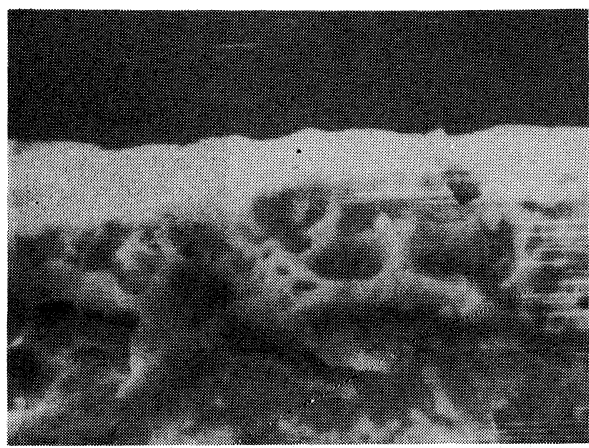

6) Paste- 9 on fired dielectric past

PHOTO 5 Electron micrographs of cross sections of fired gold paste.

dielectrics was evaluated in terms of resistance to ultrasonic washing. For this purpose, samples were made in the pattern of Figure 1(d), and were ultrasonically washed in PERCLENE as shown in Figure 4.

The samples were taken out of the PERCLENE bath at 5, 15, 30, 45 and 60 minutes after the start, and the adhesion was evaluated by the time that the line disconnection began to occur.

An ultrasonic wave at $29 \mathrm{kHz}$ was generated by an ultrasonic generator at an output level of $150 \mathrm{~W}$. The results shown in Table $I$ indicate:

1) On alumina substrates, the higher the glass content of paste was, the stronger the adhesion was. 


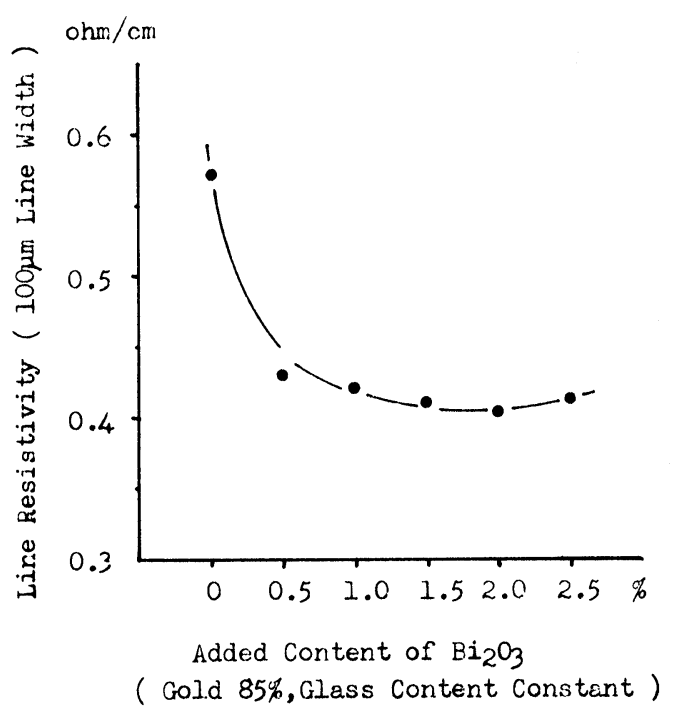

FIGURE 3 Line resistivity vs. added content of $\mathrm{Bi}_{2} \mathrm{O}_{3}$.

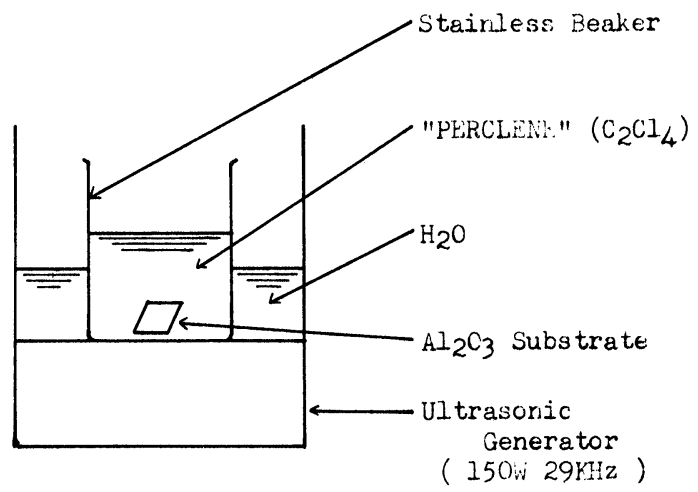

FIGURE 4 Ultrasonic washing resistance test.

2) On alumina substrates, the addition of $\mathrm{Cu}_{2} \mathrm{O}$, $\mathrm{MgO}, \mathrm{SiO}_{2}, \mathrm{Bi}_{2} \mathrm{O}_{3}$ and $\mathrm{CdO}$ had favorable effect on adhesion.

3) On dielectric layers, the lower the glass content of paste, the stronger the adhesion was.

4) The addition of $\mathrm{Bi}_{2} \mathrm{O}_{3}$ was effective in improving adhesion of paste to dielectric layers.

\subsection{Wire Bondability}

Printed and fired samples of the pattern of Figure 1(b) were made for bonding tests. And $25 \mu$ m diameter gold wire was bonded between 2 Pads of $2 \mathrm{~mm}$ square by a Model NTC thermal compression type bonder made by Kaijo Denki. The test conditions for the first bonding

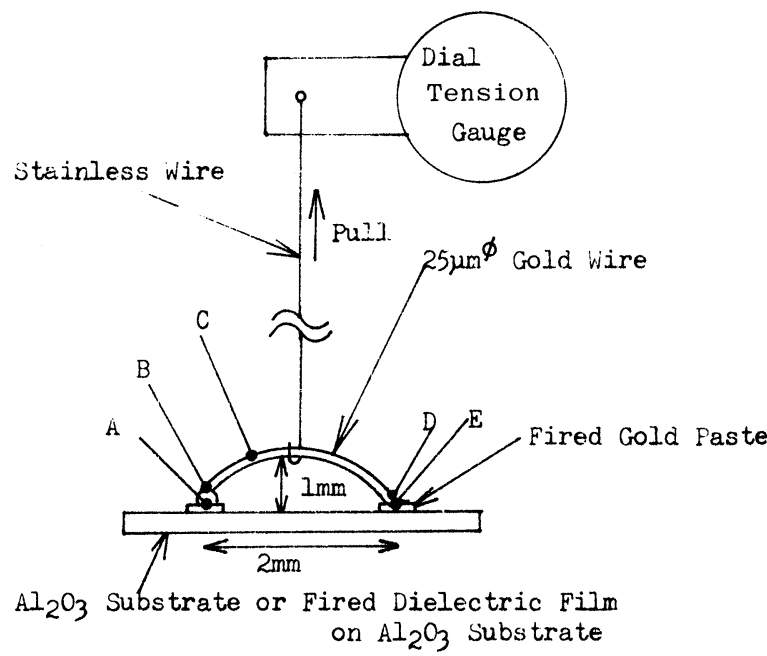

FIGURE 5 Wire-bonding strength test.

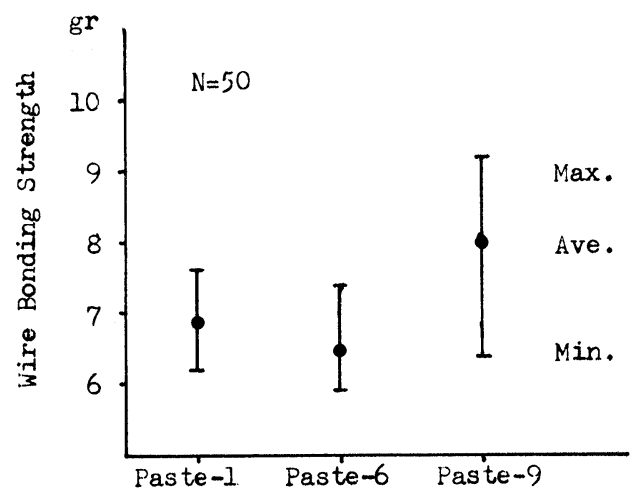

\begin{tabular}{lccc}
\hline \multirow{2}{*}{$\begin{array}{l}\text { Failure } \\
\text { mode }\end{array}$} & \multicolumn{2}{l}{ Number of failure modes } \\
\cline { 2 - 4 } & Paste-1 & Paste-6 & Paste-9 \\
\hline A & 7 & 10 & 2 \\
B & 18 & 16 & 9 \\
C & 20 & 18 & 37 \\
D & 4 & 5 & 2 \\
E & 1 & 1 & 0 \\
\hline
\end{tabular}

FIGURE 6 Comparison of wire-bonding strength on dielectric film fired on $\mathrm{Al}_{2} \mathrm{O}_{3}$ substrate.

were $100 \mathrm{~g}$ load, $350^{\circ} \mathrm{C}$ and 0.3 seconds, and for the second bonding were $200 \mathrm{~g}$ load, $350^{\circ} \mathrm{C}$ and 0.3 seconds.

Bonding strength was measured by a dial tension gauge made by CORREX, as shown in Figure 5.

Gold wires were broken at five failure modes, A through E, as shown in Figure 5.

The results of the measurements are shown in Table 1 in mean values. For the three main paste samples, the 
maximum and minimum bonding strength values, mean values, and the failure modes are shown in Figure 6. As can be seen from these results;

1) The higher the gold content of paste the higher its strength was.

2) The smaller the glass content of paste, the higher its strength was.

\section{DISCUSSION}

\subsection{Gold Powder}

One of the reasons for the improvement of various characteristics of gold paste as realized in the present experiments lies in the improvement in gold powder.

As can be seen from Photo 1, while Powder A consists of spheres with coarse surface, Powder B consists of smooth-surfaced spherical grains. The smoother surface favorably affects printability, and the lower vehicle absorption rate resulting from smooth surface is thought to have reduced shrinkage.

Generally the mixed presence of grains of different sizes at limited extent is considered to improve the porosity and to lower the resistance of the fire film.

\subsection{Glass Frit}

Although the addition of a small amount of glass frit was beneficial for printability and adhesion to alumina substrates, it had rather negative effects on other characteristics.

Especially, with respect to the adhesion strength and wire bondability on dielectrics, fritless type paste was better than fritted type paste.

The most significant difference between fritted type paste and fritless type paste is in their adhesive mechanism ${ }^{6}$. With fritted type paste, the adhesion between metal and glass is based on the network formed of molten glass, and that between glass and substrates is based on the penetration of glass into the substrate. On the other hand, with fritless type paste, adhesion is based on the formation of metal aluminate between alumina and metal oxide. Mixed bond type paste has both these mechanisms.

When the mean size of glass grains is smaller than $1 \mu$, glass sintering temperature is lowered and hence molten glass covers the surface too early at temperatures not sufficiently high enough to allow degassing, resulting in bubbles in the fired paste layer.

\subsection{Vehicle}

Normally, gold paste contains $5-15 \%$ vehicle, but

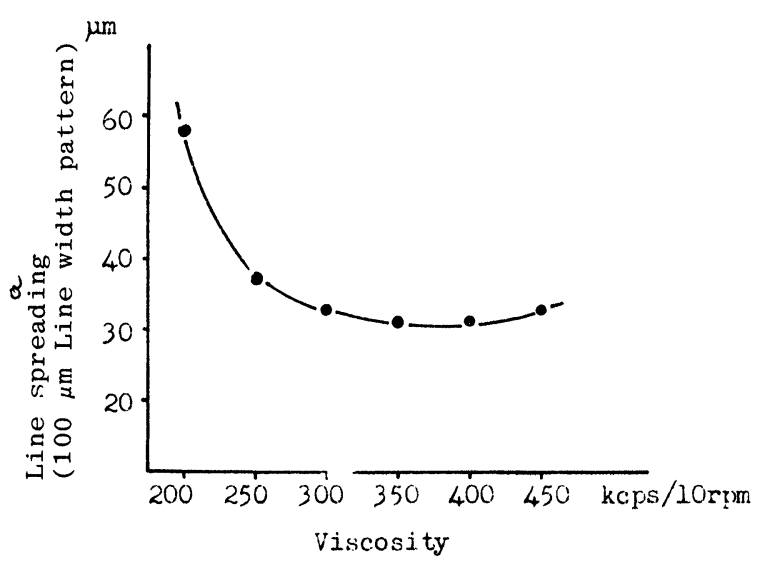

FIGURE 7 Line spreading vs. viscosity.

lower vehicle content is advantageous for reducing shrinkage.

When vehicle viscosity is low, printed lines tend to spread, but when it is too high, printed lines tend to spread during the screen removing process.

An example of the correlation between viscosity and line spread of Paste 6 as measured under the same conditions as before is shown in Figure 7.

\subsection{Additives}

$\mathrm{Bi}_{2} \mathrm{O}_{3}$ itself has a melting point of $825^{\circ} \mathrm{C}$, and when it is once melted, its viscosity decreases sharply and acts somewhat as flux. When it is added in small quantity, it helped gold powder and glass to come into closer contact, and in this way it was very effective in reducing the resistivity and porosity of fired films.

$\mathrm{Cu}_{2} \mathrm{O}$ was effective in improving the adhesion of fired films, but when it was added excessively, the surface became tarnished.

$\mathrm{MgO}, \mathrm{SiO}_{2}, \mathrm{CdO}$, etc. had the same effects as described earlier.

\section{CONCLUSION}

Under a development program for gold conductor paste for high-density circuit applications, several gold conductor compositions were made based on improved gold powder and adjusted contents.

Mixed bond type paste was confirmed to be advantageous when used on alumina substrates, and fritless paste was found to be superior when used on dielectrics.

With these types of paste, a fine line printability of $70 \mu \mathrm{m}$ line width and spacing was possible under 
usual production conditions, and $50 \mu \mathrm{m}$ was confirmed to be possible under specially controlled conditions, at a small sacrifice of productivity.

\section{ACKNOWLEDGEMENT}

The authors thank Mr. M. Kobayashi, Director of the Electronic Metal Division of Sumitomo Metal Mining Co., Ltd. for his permission to publish this paper.

\section{REFERENCES}

1. J. P. Redmond, D. M. Andrews and C. P. Brooks, "Gold Metallization of Ceramics", Proceedings of Electronic Components Conference, 383-387 (1972).
2. R. Kersey, "The Fabrication of Multilayer Structures Using Various Film Technologies", Proceedings of Electronic Components Conference, 198-203 (1973).

3. R. Webster, "Fine Line Screen Printing Yields as a Function of Physical Design Parameters", Proceedings of International Microelectronics Symposium (ISHM, 187-198 (1974).

4. K. Kurzweil and J. Loughran, "Thick Film Pastes for Multilayer Use", Proceedings of Electronic Components Conference, 212-219 (1973).

5. R. H. Zeien, "Characterization of Thick Film Fritless Metallization", Proceedings of International Microelectronics Symposium (ISHM), 7-15 (1974).

6. B. R. Smith and R. L. Dietz, "An Innovation in Gold Paste", Proceedings of ISHM Symposium, 5-8, 2-A-5-1-5-8 (1972). 

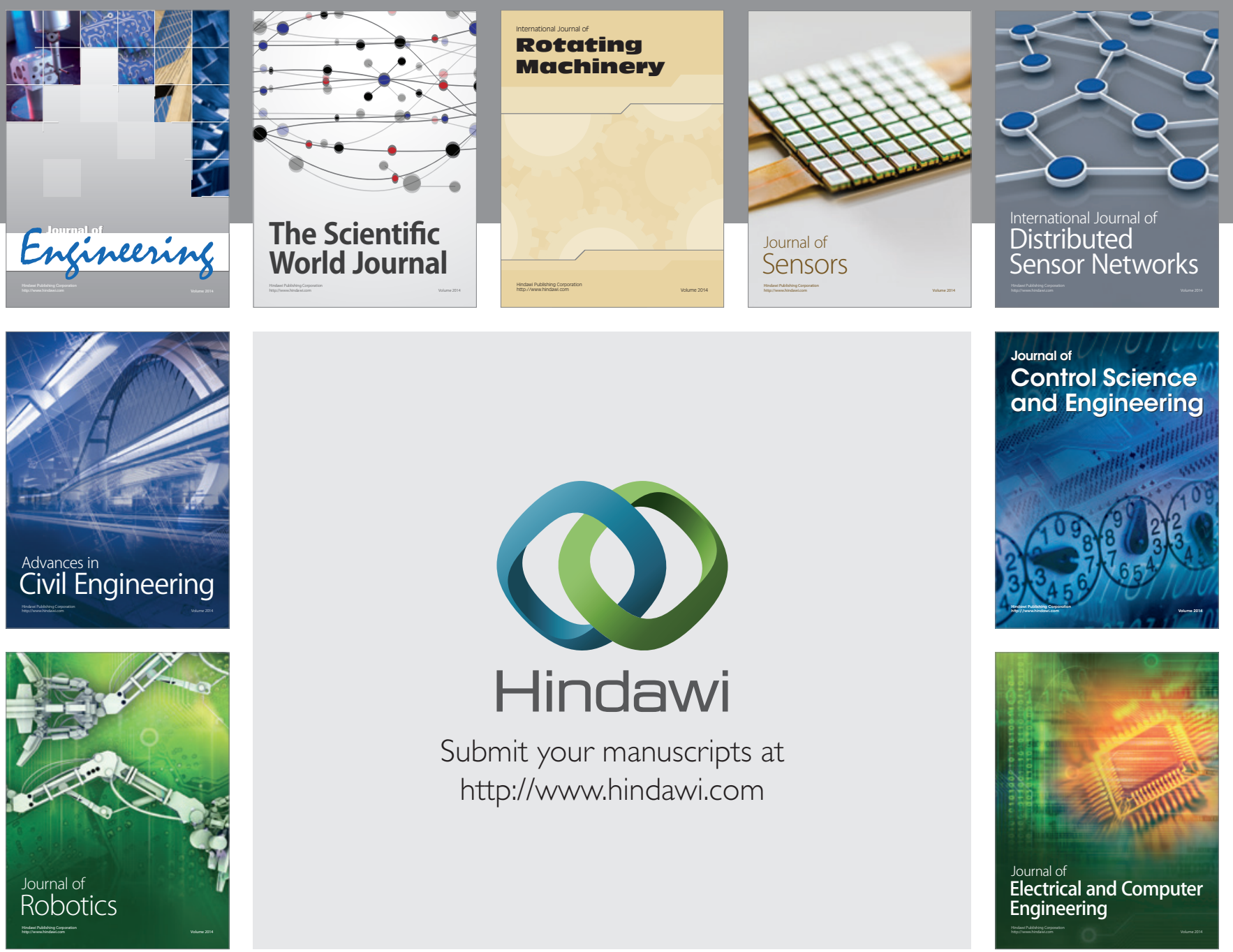

Submit your manuscripts at

http://www.hindawi.com
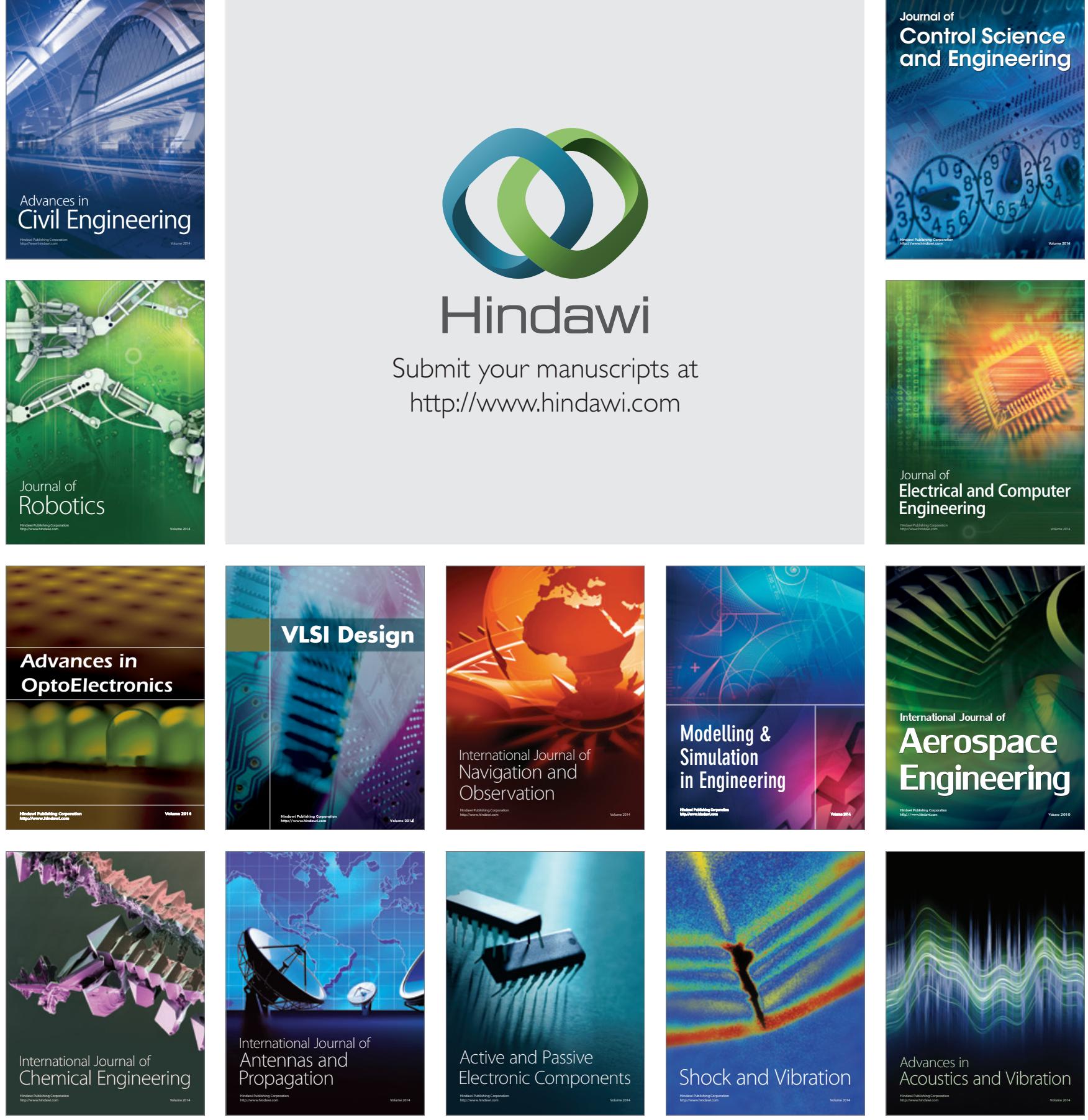